\title{
Parenteral antibiotics at home
}

\section{David FM Looke}

Infectious diseases

physician and clinical

microbiologist

Infection Management

Services ${ }^{\top}$

Associate professor ${ }^{2}$

David AJ McDougall

Senior pharmacist

Infection Management

Services'

Pharmacy Department

'Princess Alexandra

Hospital

Brisbane

2 Department of Medicine

University of Queensland

\section{Key words}

antibiotic resistance,

methicillin-resistant

Staphylococcus aureus

Aust Prescr 2012;35:194-7

\section{SUMMARY}

Giving parenteral antibiotics to patients at home compared to in hospital presents unique challenges.

The number of visits a health professional can make to a patient's home per day and the stability of an antimicrobial drug in solution may restrict the choice of therapy.

Novel administration methods and devices allowing bolus dosing or continuous infusions can be used to enable convenient and practical home treatment of many serious infections that have no oral therapy available.

Identifying suitable patients and antimicrobials as well as appropriate monitoring is key for treatment to be successful.

\section{Introduction}

Outpatient intravenous antimicrobial therapy has been practised in the USA since the 1970s and in Australia since the mid-1990s. A number of infections, such as acute cellulitis, lower respiratory tract infections and exacerbations of bronchiectasis, osteomyelitis and infective endocarditis, can now be treated safely at home.

Many infections can be treated orally. However, because of increasing antibiotic resistance, many infections that were once treated with oral antibiotics have to be treated parenterally.

\section{Models of care}

A number of programs for home-based therapy have been developed. They can be roughly divided into three categories:

- healthcare professionals visit a patient's home regularly to administer therapy

- patient administers their own therapy at home after successful training

- patient attends regular appointments at the hospital for treatment.

The first category, in which nurses and other health professionals visit patients to administer treatment, dominates in Australia and was first adopted in Victoria in 1994.' Other programs do exist and the patient self-administration model is an attractive option in Australia given large geographical areas and long distances between regional areas and metropolitan hospitals.

\section{Patient selection}

The selection of patients for admission to home programs is the key to ensuring that complications that require urgent intervention in the acute hospital environment are minimised. The following points need to be addressed before admission into a program:

1. It needs to be confirmed that parenteral antibiotics are truly required and that effective oral therapy cannot be given. Many conditions such as pneumonia and osteomyelitis can be effectively managed with oral antibiotics.

2. The patient needs to be well enough to be at home. Comorbidities such as unstable diabetes, relative hypoxaemia, severe pain, cognitive dysfunction and visual or auditory handicap are contraindications.

3. The patient has to be willing to accept the program. Obligations of the patient and program of care should be discussed with the patient and carer.

4. The home environment must be suitable. There needs to be a clean, light area where intravenous line access can be performed. There also needs to be a refrigerator, telephone and a carer who is able to contact the program in an emergency.

5. Distance of the patient's home from the treating centre needs to be taken into account in terms of frequency of visits.

6. A clear understanding of medical responsibility is essential. Many programs have their own medical staff and patient care responsibility is transferred to a doctor working in the program. Other programs are led by non-medical healthcare professionals and medical responsibility remains with the referring doctor.

7. Home care should never be accepted when it is second best to inpatient management. Transfer to a home program when a patient threatens selfdischarge is strongly discouraged. Reasons for the patient's desire to self-discharge against advice should be carefully sought and advice to remain in hospital should be communicated in a culturally appropriate and non-judgemental fashion.

8. The presence of substance abuse such as alcoholism or illicit drugs is a contraindication. 
9. Appropriate intravenous access is essential. In some circumstances, daily cannulation for once-daily intravenous therapy when the duration of therapy is likely to be only a few days may be the simplest option. Peripheral intravenous cannulae left in situ in the patient's home are generally not a good option as they are less able to be well secured, have higher risks for infection or thrombophlebitis, and should be changed regularly. Patients requiring longer courses of therapy generally require a device that can remain in situ for a longer period of time. Peripherally inserted central cannulae have revolutionised intravenous antibiotic administration at home, and have in general low rates of complications. Increasingly, insertion of lines is performed in radiology departments where ultrasound guidance allows insertion into large veins in the upper arm, under full aseptic conditions. Other patients who may require frequent treatment courses for chronic conditions, such as cystic fibrosis, will have long-term tunnelled catheters such as Portacaths or Hickman lines.

\section{Indications for home intravenous therapy}

Only a small number of bacterial infections need to be treated with intravenous antibiotics in the home. Many mild to moderate infections can be effectively treated with oral antibiotics. For example, mild to moderate pneumonia can generally be treated orally, and even more severe cases can be changed from intravenous medications to oral once the patient is stable. ${ }^{2}$ Similarly, urosepsis such as pyelonephritis can often be treated with oral drugs initially if the patient is stable and not vomiting, or changed to oral therapy once stable and the microbiology results are available. ${ }^{2}$

Streptococcal cellulitis often does not respond to oral therapy, and in the absence of severe sepsis or comorbidity it is a suitable condition for initial intravenous antibiotics at home (Table 1). For example, once-daily intravenous cefazolin plus oral probenecid is effective for moderate to severe cellulitis. ${ }^{3}$

Patients who have been treated and stabilised in hospital and require prolonged courses of intravenous antibiotics are commonly treated at home. Examples of indications include infective endocarditis, osteomyelitis, infected prosthetic material, brain, lung and liver abscess, exacerbations of bronchiectasis or cystic fibrosis, and specific diseases such as melioidosis. Examples of intravenous antibiotic regimens given at home are listed in Table 1.

\section{Antibiotic resistance}

Unfortunately because of the increasing incidence of antibiotic resistance in hospitals and the community, many infections that once had oral antibiotic options now only have parenteral drugs available. The rise of community-acquired methicillin-resistant Staphylococcus aureus, multidrug resistant Escherichia coli urosepsis and multidrug resistant tuberculosis means that long courses of intravenous antibiotics are needed. This situation is becoming more frequent as the development of new antimicrobial drugs has all but come to a halt.

\section{Antibiotic selection}

When choosing an antibiotic, evidence-based guidelines should be followed. ${ }^{2}$ Only when the preferred therapy cannot be given in the home should an alternative broad spectrum drug be used.

The resources of the home program may affect the choice of antibiotic. In practice, most services will only be able to visit a patient once a day, few can visit more often. The two key factors in assessing whether an antibiotic is appropriate for use in a home program are drug stability and administration intervals. Other factors, including toxicity and whether adequate monitoring is possible, are also important.

\section{Stability}

Antibiotics must be sufficiently stable for the duration of the infusion or for extended periods if manufactured in advance. Stability is usually defined as greater than $90 \%$ of the original concentration remaining at the end of the infusion. Ampicillin and

\section{Table 1 Examples of infections and treatments used in hospital in the home}

\begin{tabular}{|c|c|}
\hline Condition & Treatment \\
\hline Viridans streptococcal endocarditis & Benzylpenicillin $10.8 \mathrm{~g}$ daily by continuous IV \\
\hline MSSA blood stream infection & Flucloxacillin $8 \mathrm{~g}$ daily via continuous IV \\
\hline MSSA infective endocarditis & Flucloxacillin $12 \mathrm{~g}$ daily via continuous IV \\
\hline ESBL Escherichia coli UTI & Ertapenem $1 \mathrm{~g}$ daily as an IV bolus \\
\hline Streptococcal cellulitis & $\begin{array}{l}\text { Cefazolin } 2 \text { g IV daily with oral probenecid } \\
1 \mathrm{~g} \text { daily }\end{array}$ \\
\hline MRSA septic arthritis & $\begin{array}{l}\text { Vancomycin } 1.5 \mathrm{~g} \text { twice daily or } 2-3 \mathrm{~g} \text { daily via } \\
\text { continuous IV (adjust for renal function and titrate } \\
\text { to plasma concentrations) }\end{array}$ \\
\hline Diabetic-foot osteomyelitis & $\begin{array}{l}\text { Ticarcillin/clavulanic acid } 12.4 \mathrm{~g} \text { daily via } \\
\text { continuous IV }\end{array}$ \\
\hline Bronchiectasis exacerbation & Ceftazidime $6 \mathrm{~g}$ daily via continuous IV \\
\hline Pneumococcal pneumonia & $\begin{array}{l}\text { Benzylpenicillin } 7.2 \mathrm{~g} \text { daily by continuous IV OR } \\
\text { ceftriaxone } 1 \mathrm{~g} \text { daily IV }\end{array}$ \\
\hline \multicolumn{2}{|c|}{ MSSA methicillin-sensitive Staphylococcus aureus } \\
\hline \multicolumn{2}{|c|}{ MRSA methicillin-resistant Staphylococcus aureus } \\
\hline \multirow{2}{*}{\multicolumn{2}{|c|}{$\begin{array}{ll}\text { ESBL } & \text { extended spectrum beta-lactamase producing } \\
\text { UTI } & \text { urinary tract infection }\end{array}$}} \\
\hline & \\
\hline \multicolumn{2}{|l|}{ IV intravenous administration } \\
\hline
\end{tabular}


amoxicillin are commonly used in hospitals but are unsuitable for home programs given their low stability in aqueous solution. ${ }^{4}$

The stability of many antibiotics is temperature dependent and whilst they may be stable in a refrigerator for extended periods they can rapidly degrade at room and body temperature. This is an important consideration when giving continuous infusions. During an infusion, temperatures can reach more than $31^{\circ}$ C. ${ }^{5,6}$ Benzylpenicillin, for example, is a useful antibiotic to treat many streptococcal and enterococcal infections. However unless the antibiotic is compounded using a buffer, it rapidly degrades with $1-5 \%$ remaining after 24 hours at body temperature. ${ }^{6,7}$

Meropenem, a carbapenem drug that is often required to treat multidrug resistant pathogens, is poorly stable in solution and is unsuitable for continuous infusions. ${ }^{8}$ A strategy where it is compounded and kept in the patient's refrigerator, then given eighthourly rather than as a continuous infusion, helps overcome this problem. Continuous infusion with the bag of meropenem inside an ice pack has also been attempted. A large body of information exists on drug stability and specialty pharmacy services may be able to assist.

\section{Administration intervals}

If the patient can only be visited once a day, prescribing of antibiotics is limited to either oncedaily bolus dosing or 24-hour infusions. The optimal method of administering an antibiotic will depend upon the pharmacological properties of the drug which can be separated into three categories concentration-dependent killing, total exposure and time-dependent killing (Table 2). ${ }^{9}$

Bolus administration is appropriate for antibiotics that exhibit concentration-dependent killing. Aminoglycosides require high peak concentrations to maximise their effectiveness, but have a prolonged post-antibiotic effect. This allows time for the drug to be washed out, thereby minimising toxicity.

Continuous infusions are appropriate if the antibiotic effectiveness is determined by the time $(T)$ that the antibiotic remains above the minimum inhibitory concentration (MIC) and the drug is sufficiently stable. For example, beta-lactams (penicillins, cephalosporins and carbapenems) display this property so can be administered via continuous infusion. Unfortunately not all the beta-lactams are stable for 24 hours in solution.

Twice-daily infusions of vancomycin or similar can be managed using programmable continuous ambulatory delivery pumps where the day's supply of vancomycin is delivered as two infusions 12 hours apart. Given the practicalities of many home services however, continuous infusions are often used and evidence is emerging that this method is satisfactory although comparative trials are lacking.

\section{Monitoring}

Monitoring patients enrolled in home programs is crucial to maximise efficacy and minimise toxicity. Therapeutic drug monitoring should be undertaken at least weekly for vancomycin and usually more often for aminoglycosides. There are very few indications such as multidrug resistant tuberculosis that warrant long-term aminoglycoside treatment and alternative antibiotics should always be used if appropriate. ${ }^{2}$ Aminoglycoside toxicity is related to duration of therapy and patients being treated for longer than five days are at significantly increased risk of both renal and vestibular ototoxicity. Close monitoring including weekly audiometry is recommended. Therapeutic drug monitoring is available throughout Australia for other antibiotics including beta-lactams and teicoplanin, and may be useful in certain patients upon specialist advice.

Table 2 Drug administration intervals and pharmacological properties

\begin{tabular}{|c|c|c|c|}
\hline Pharmacological property & Goal & Examples & Administration method \\
\hline Concentration-dependent killing & $\begin{array}{l}\text { Maximise the concentration above the minimum } \\
\text { inhibitory concentration (Cmax:MIC) }\end{array}$ & Aminoglycosides & Intermittent \\
\hline Total exposure & $\begin{array}{l}\text { Maximise the total exposure of the body to the } \\
\text { antibiotic (AUC:MIC) }\end{array}$ & $\begin{array}{l}\text { Vancomycin } \\
\text { Fluoroquinolones }\end{array}$ & Intermittent/ continuous infusions \\
\hline Time-dependent killing & $\begin{array}{l}\text { Maximise the time the concentration is above } \\
\text { the minimum inhibitory concentration ( } T>M I C)\end{array}$ & $\begin{array}{l}\text { Beta-lactams } \\
\text { Lincosamides }\end{array}$ & Continuous infusions \\
\hline $\begin{array}{ll}\text { Cmax } & \text { maximum plasma drug co } \\
\text { MIC } & \text { minimum inhibitory conce } \\
\text { AUC } & \text { area under the plasma dru } \\
T & \text { time }\end{array}$ & $\begin{array}{l}\text { entration during a dosing interval } \\
\text { ration } \\
\text { concentration-time curve }\end{array}$ & & \\
\hline
\end{tabular}




\section{Potential harms}

There are several risks for patients being treated in the home with intravenous antibiotics. Non-compliance with the non-antibiotic aspects of treatment such as bed rest, limb elevation and dressing changes can be a problem. Adverse events related to the venous access device are also of concern. A safety audit at our institution in 2009 revealed that approximately $5 \%$ of patients experienced a complication with their peripherally inserted central catheter lines (for example clots, infections) - this equates to less than 1 per 1000 catheter days. Adverse drug reactions including anaphylaxis are also potential risks. Generalised skin eruptions from long courses of penicillins, cephalosporins and carbapenems may arise some weeks after starting therapy and may be heralded by a rising eosinophil count.

\section{Conclusion}

The treatment of infections with intravenous antibiotics in the home is an established treatment modality. Careful patient selection, safe intravenous access and appropriate training and monitoring means that many patients can be treated at home. Unfortunately, the rise of multidrug resistant infections means more patients will need prolonged courses of intravenous antibiotics. $<$

Conflict of interest: none declared
SELF-TEST QUESTIONS

True or false?

5. Meropenem can be given as a 24-hour continuous infusion. 6. Ampicillin is not suitable for hospital in the home because of stability problems.

Answers on page 211

\section{REFERENCES}

1. Montalto M. The 500-bed hospital that isn't there: the Victorian Department of Health review of the Hospital in the Home program. Med J Aust 2010;193:598-601.

2. eTG complete [internet]. Melbourne: Therapeutic Guidelines Limited; 2010.

3. Grayson ML, McDonald M, Gibson K, Athan E, Munckhof WJ, Paull P, et al. Once-daily intravenous cefazolin plus oral probenecid is equivalent to once-daily intravenous ceftriaxone plus oral placebo for the treatment of moderateto-severe cellulitis in adults. Clin Infect Dis 2002;34:1440-8.
4. Bing C, Chamallas S, Hayes J, Limburg-Mancini B, Nitzki-George D, Nowobilski-Vasilios A, et al. Extended stability for parenteral drugs. 3rd ed. Bethesda: American Society of Health-System Pharmacists; 2005.

5. Poole SG, Dooley MJ. Drugs in ambulatory infusion devices. Aust J Hosp Pharm 1999;29:328-9.

6. Vella-Brincat JW, Begg EJ, Gallagher K, Kirkpatrick CM, Zhang M, Frampton C, et al. Stability of benzylpenicillin during continuous home intravenous therapy.

J Antimicrob Chemother 2004;53:675-7.
7. McDougall D, McWhinney B. Stability of buffered benzylpenicillin solution for home intravenous therapy. Melbourne: Australian Society for Antimicrobials; 2011.

8. Keel RA, Sutherland CA, Crandon JL, Nicolau DP. Stability of doripenem, imipenem and meropenem at elevated room temperatures. Int J Antimicrob Agents 2011;37:184-5.

9. Nicolau DP. Optimizing outcomes with antimicrobial therapy through pharmacodynamic profiling. J Infect Chemother 2003;9:292-6.

\section{Book review}

\section{Gone viral: the germs that share our lives}

\section{Frank Bowden}

Sydney: NewSouth Books; 2011.

\section{4 pages}

You would be forgiven for thinking that a book about 'bugs' is boring. From his basic training in infectious diseases at St Vincent's Hospital in Melbourne, through life in the Northern Territory coordinating sexually-transmitted disease programs, to working as a staff specialist in Canberra, Frank Bowden's colourful memoir is anything but boring.

If you've ever wondered what happened to SARS (Severe Acute Respiratory Syndrome) or asked yourself why smallpox is the only disease to be eradicated by vaccination, this is the book for you. Swine flu, meningitis, MRSA (methicillin-resistant Staphylococcus aureus), necrotising fasciitis and donovanosis are but a few diseases you will encounter. Anecdotal stories bring this fascinating, terrifying and sometimes just plain gross topic to life. It is hard not to laugh out loud in parts, particularly when Professor Bowden describes the time he saw his first case of 'saxophone penis'. However, it is not all fun and games. The chapter 'Life during wartime' is more sombre as he recounts life on the wards in the 1980s during the HIV epidemic. Or the time he was called to the morgue to a schoolboy who went to bed feeling unwell only to be found dead in the morning from overwhelming meningococcal sepsis.

The statistics on syphilis, gonorrhoea and chlamydia in Aboriginal women will shock you. Frank Bowden shares his sometimes controversial views on infection control and the 'triumphs and failings' of the health system in these communities.

Despite it being a page turner, I did feel some points were laboured - the author dedicates a whole chapter to his personal experience of a needlestick incident during the initial years of HIV. I also skimmed the chapter on hand hygiene in hospitals despite its interesting historical references to puerperal sepsis. This easy-to-read, witty account of life in a world of germs, complete with a glossary and index, has wide appeal. If you are a clinician, public health enthusiast or just wanting to know the facts behind the headlines, this book is as entertaining as it is informative and is perfect for a Sunday afternoon read.

\section{Fiona G Mackinnon PhD} (Microbiology)

Deputy editor

Australian Prescriber

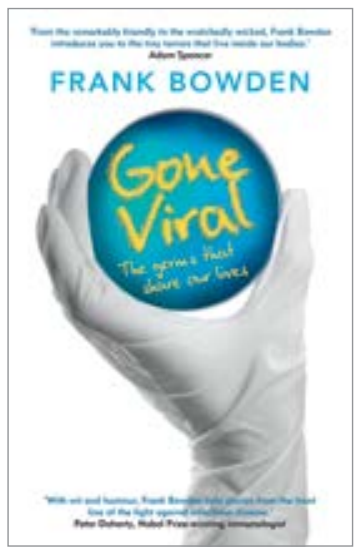

